\title{
Petrographic assessment of coal gas content
}

\author{
Volodymyr Baranovskyi ${ }^{1,{ }^{*}}$, and Liubov Kuznetsova ${ }^{1}$ \\ ${ }^{1}$ Institute of Geotechnical Mechanics named by N. Poljakov of National Academy of Sciences of \\ Ukraine, 49005, Dnipro, Simferopolska Str., 2a, Ukraine
}

\begin{abstract}
Traces of the gas generation process on natural coal burstings have been identified and documented using the petrographic method. Their characteristic features were described. The methodology of their quantitative calculation is proposed in order to assess the modern gas content of coals.
\end{abstract}

\section{Introduction}

Throughout the geological history of coal beds the transformation of the initial plant material under the influence of temperature and pressure is accompanied by the emission of gaseous products.

According to the opinion of many researchers, the volumes of coal-generated gas are quite significant - they are by stages of coalification $\left(\mathrm{m}^{3} / \mathrm{t}\right)$ : Lignite- 68 , Subbituminous150, Bituminous C-230, Bituminous B-270, Antracite-420. Most of the methane (over $90 \%$ ) migrates to host rocks. To date, up to $10 \%$ of this amount has been preserved in the coal-bearing strata [1].

Migration of gases from the place of generation or accumulation due to elevated pressures is always directed towards unloading along the shortest way - vertically to fracture zones, to the arches of anticlines, to the erosion of coal-bearing layers and, first of all, to the bedding of permeable horizons, upwards through the rise of beds [2].

However, all these data are based on theoretical concepts and vary among different researchers.

Such volumes of gas generated by coal leaving the bed $(90 \%)$ and remaining in it $(10 \%)$ could not leave traces of their presence in the coal structure. Unfortunately, perhaps the only source that in details (with confirmation by photographic materials) describing this phenomenon, can be considered the paper of Shulha V.F., Lukin A.E., Lelyk B. I. [3], who met "signs of gas emission" in the argillilites of the coal-bearing formation of the LvivVolyn basin.

Thus, the actual confirmation of the gas generation process by coals and the possibility of a quantitative assessment of this process are currently relevant and is the purpose of this paper.

*Corresponding author: gvrvg@meta.ua 


\section{Methodology}

To solve the problem, a technique based on the algorithm ISO $7404-1-84$ was proposed in [6]:

1. Sampling, sample preparation and selection of the sub-sample for analysis - in accordance with ISO $7404-1-84$;

2. The plastic ring is filled with plasticine;

3. The surface of the plasticine is covered with a uniform layer of coal particles, prepared in paragraph 1 ;

4. Using a laboratory press, the coal particles are pressed into the plasticine, while some of them will be horizontal position and we get a sufficient number of unpolished surfaces of coal particles suitable for microscopic research;

5. The resulting preparation is leveled on a glass slide;

6. Under the microscope, we are moving the preparation each time across the field width of view (this allows to evenly cover the preparation with the observation points), choose a coal particle with maximum image clarity and take a micrograph after pre-calibrated the microscope using an object micrometer for reflective light;

7. In the graphic editor (Photoshop), we leave only this particle on the image, deleting everything else, save the resulting image;

8. Having zoomed in the image of a coal particle, we select traces gas on it. We save the image only of the selected traces gas;

9. According to the free program ImageJ (Research Services Branch, National Institute of Mental Health, Bethesda, Maryland, USA) [7] we calculate the square of the particle, the square of traces gas and the quantity of traces gas. The obtained data we record in the table. Then, to characterize the traces gas, we calculate two new indexes proposed by us -1$), Q_{c}$ - the quantity of traces gas per $\left.100 \mathrm{mcm}^{2}, 2\right), A_{c}$ - the degree of infestation of the gelified substance (microcomponents of the vitrinite group) with traces gas, calculated as the ratio of the trace gases footprint to the total square of the entire particle.

\section{Results and Discussion}

As a result of petrographic research, we identified "traces" of gas generation on the surfaces of natural coal burstings from the whole range of coalification (from Lignite to Metaantracite) [4, 5]. These newly formed elements of the coal structure (cavities) are in the form of bubbles, craters or cone funnels (Fig. 1). The presence of a "tail" in the gas bubble in the coal, i.e. the crack propagation by pressure-energized, is the main difference between them and the bubbles on the free surface of substances subjected to heating in laboratory conditions.
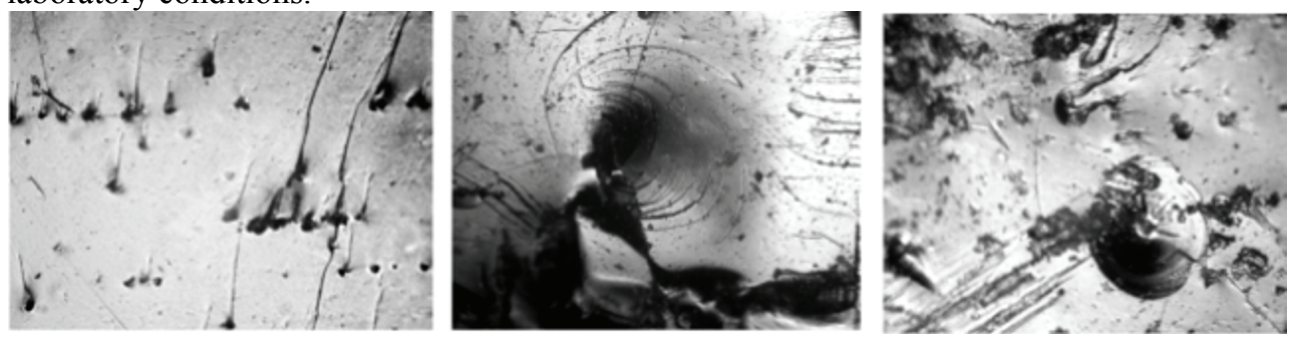

Fig. 1. The traces form of gas generation activity in coals, the size of each image $-283 \times 213$ microns.

Depending on the stresses available in the coal and the size of the expansion pressure, the length of the "tail" varies widely. (Fig. 2). 

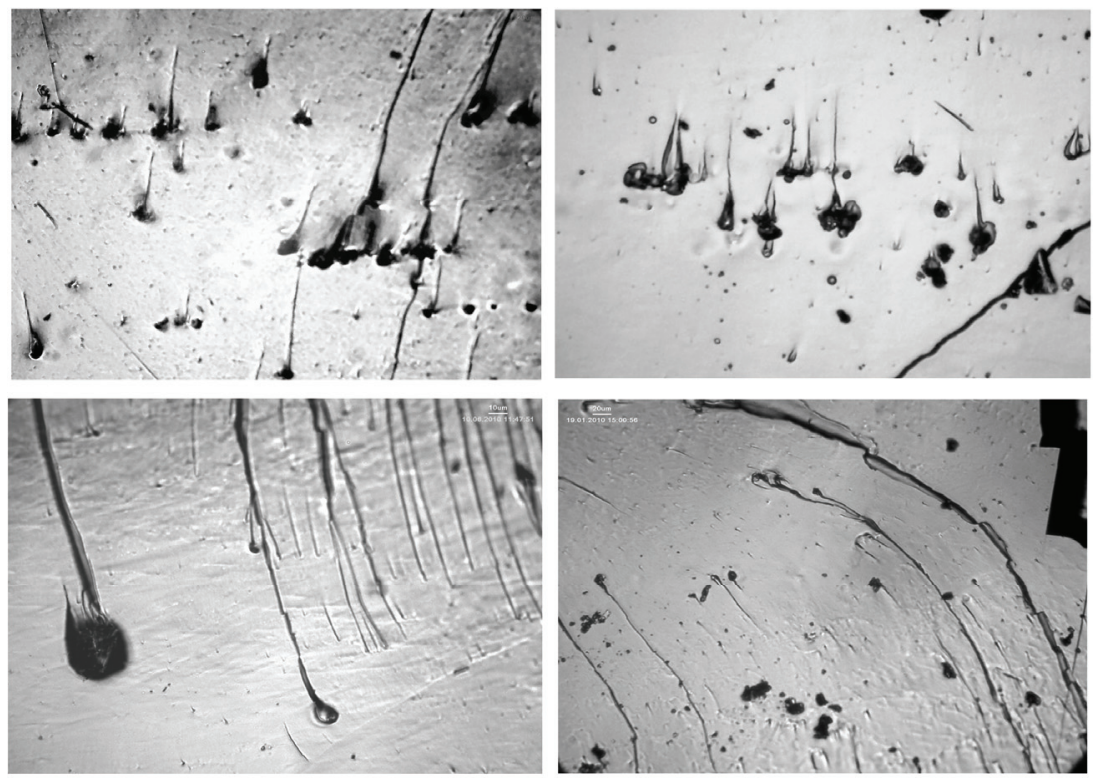

Fig. 2. Cracks of various sizes, initiated by the pressure of the gas expansion, the size of each image $283 \times 213$ microns.

In one coal bed, the quantity of traces gas is distributed unevenly both upon the thickness of the bed and along the strike, i.e. we cannot judge the quantity of traces gas in a particular bed intersection by one piece of the coal. Coals of the same rank, but of different beds, may differ significantly in the quantity of traces gas. Thus, Figure 3 shows microimages on the surface of the coal beds samples $l_{4}$ (atop) and $m_{3}$ (below) from the O.F. Zasiadko mine. The coals of both beds are classified as Bituminous rank, and have approximately equal content of vitrinite. The difference in the petrographic composition, namely, the different content of inertinite and liptinit indicates the difference in the initial composition and transformation conditions. In this case, it is logical to assume that the vitrinite of both beds is different in properties, which has influence in the different gas generation ability.

Thus, as a result of coal-petrographic researches, we identified new structural elements in the coal substance - traces of the gas generation process ("gas bubbles"). Theoretically, the mechanism of formation of "gas bubbles" can be explained from the point of view of the kinetic theory by Academician Ya.I. Frenkel [8]. In his opinion, the lentil-like cavity, which is formed as a result of the instantaneous action of tensile forces, is the basis of the bubbles appearance. The volume of the cavity is also instantly filled with gases. Since the sphere has the best ratio between the volume and the surface in comparison with other geometric shapes, the lentil-like cavity takes on a spherical shape.

Date obtained as the result of the research upon the samples of coal of all ranks does not contradict this theory (Fig. 4).

The quantity of paleotraces gas can be as an indicator of the quality of the gelified coal substance, the gas generation ability of carbonaceous components (and as a result of modern gas content), and due to the fact that the gas generation process contributes to the development of fracturing and increased traces gas near the existing cracks - the indicator of coal disturbance.

The quantity of traces gas per $100 \mathrm{mcm}^{2}$ the coal surface $Q_{c}$ characterizes the properties of the gelified substance of coals, their gas-generating ability. 

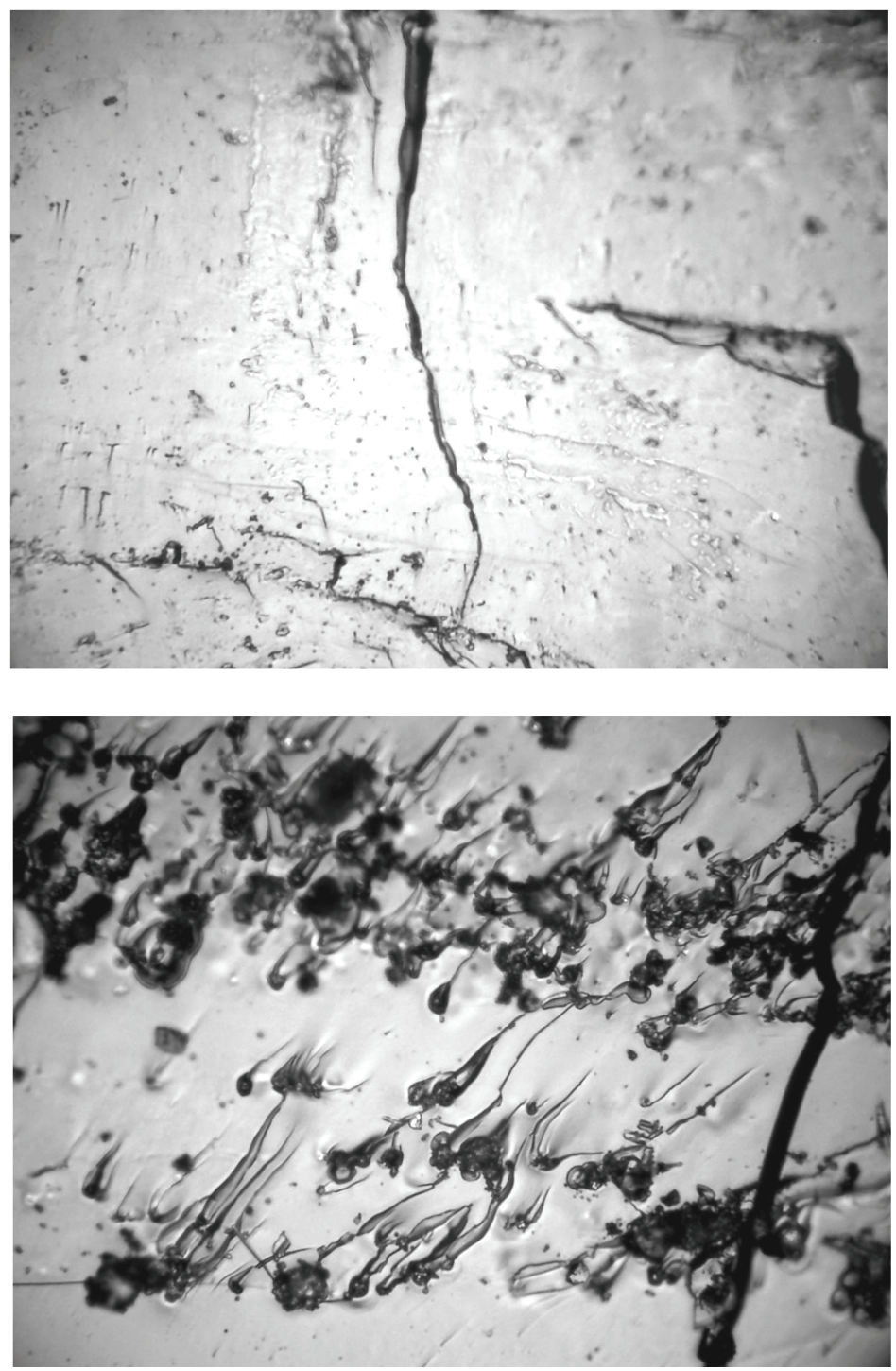

Fig. 3. The various gas generation ability of isometamorphic coal beds $l_{4}$ and $m_{3}$ at the O.F. Zasiadko mine.
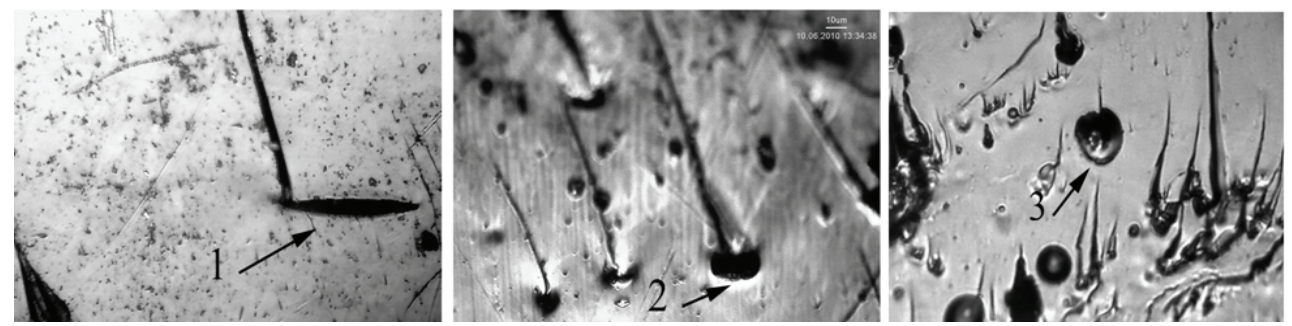

Fig. 4. Sequential $(1,2,3)$ transformation of lentil-like cavity into a sphere at the formation of a gas bubble.

The ratio of the traces gas footprint to the total surface square of the coal $A_{c}$ evaluates work that the process of gas generation and gas migration in coal beds contributes to their 
structure.

The analysis of cumulative averages values of indexes $Q_{c}$ and $A_{c}$ (i.e. the average values of these indicators for $2,3,4,5$ etc. observations) to identify a sufficient quantity of observations, i.e. the number of micrographs of the preparations surface showed that for both indicators 30 observations are enough.

The quantity and size of traces of the gas generation process depend on the degree of coalification, their size varies from micron fractions to 50 microns or more, and at the low coalification stages these are single large "traces", at medium stages both small and large traces, and in highly carbonized coals there are mostly small ones.

"Traces of gas generation" do not disappear at the stage of gasless anthracites, although their quantity is somewhat reduced relative to anthracites, containing gas.

Using a technique, similar to the method of calculating the petrographic composition in coals, a quantitative assessment of traces of gas generation was given and in the series from Lignite to low volatile Bituminous a direct dependence of their quantity on the values of modern gas content of coal beds was revealed [5].

\section{Conclusions}

A new method of petrographic assessment of coal gas content has been proposed, the essence of which is the use of optical microscopy of coal samples, with the further processing of photographic materials obtained.

On the basis of photographic materials of coal-petrography research, the presence of a gas generation process in coals has been confirmed.

The data obtained by the new method are well correlated with the known factual gasbearing data obtained by traditional methods.

The proposed method is not express and requires a certain qualification of the coalpetrographer. Currently, we are working on the unification of the proposed method in the direction of digital processing of microphotographs.

\section{References}

1. Shulga, V.F. (1981). Nizhnekarbonovaya uglenosnaya formatsiya Donetskogo basseyna. Moskva: Nauka

2. Golubev, A.A., Mayboroda, A.A., Antsiferov, V.A., Kanin, V.A. (2008). Genetic aspect of the generation of accumulations and fields of free hydrocarbon gases of the Greater Donets Basin. Naukovi pratsi UkrNDMI NAN Ukrainy, (3), 25-40

3. Shulga, V.F., Lukin, A.Y., Lelik, B.I. (2000). Fossil indicators of gas emission in coalbearing sediments of the Lviv-Volyn basin. Litologiya i poleznye iskopaemye, (5), 554560

4. Baranovskiy, V.I. (2010). Petrographic indicators of reactive carbons. Geotekhnicheskaya mekhanika: Mezhvedomstvennyy sbornik nauchnykh trudov. IGTM NAN Ukrainy, (88), 271-275

5. Bezruchko, K.A., Baranovskiy, V.I. (2014). Marks of gas-generation processes in Donbas coal. Ugol Ukrainy, (11), 31

6. GOST 9414.2-93 (ISO 7404/2-85). (1995). Methods for the petrographic analysis of bituminous coal and anthracite. Part 2. Method of preparing coal samples. Moskva: Izdatelstvo standartov

7. Computer program ImageJ. Retrieved from: http://rsb.info.nih.gov/ij/. html

8. Frenkel, Ya.I. (1975). Kineticheskaya teoriya zhidkostey. Leningrad: Nauka 